\title{
Evaporative Cracking Characteristics of the Embankment Soil Affected by the Saline Concentration
}

\author{
Jiawei Liu $\left(\mathbb{D},{ }^{1}\right.$ Yingzhi Xia $\mathbb{D}^{1},{ }^{1}$ Hui Li $\mathbb{D}^{1},{ }^{1}$ Guoping Hu $\left(\mathbb{D},{ }^{1}\right.$ and Mingming $\mathrm{Hu}\left(\mathbb{D}^{2}\right.$ \\ ${ }^{1}$ School of Civil and Transportation Engineering, Henan University of Urban Construction, Pingdingshan, China \\ ${ }^{2}$ School of Civil Engineering, Xuchang University, Xuchang, China \\ Correspondence should be addressed to Hui Li; 30070509@hncj.edu.cn and Mingming Hu; hutiaoaini@hotmail.com
}

Received 5 December 2021; Accepted 24 December 2021; Published 11 January 2022

Academic Editor: Yonghong Wang

Copyright (c) 2022 Jiawei Liu et al. This is an open access article distributed under the Creative Commons Attribution License, which permits unrestricted use, distribution, and reproduction in any medium, provided the original work is properly cited.

Embankment soil affected by saline can not only cause roadbed settlement, frosting, and road cracks but also cause corrosion and cracking of roadbed pipelines, which seriously affects the stability of the road. Water evaporation and dry cracking of the saline soil mainly cause soil swelling, poor water stability, and corrosive characteristics of the embankment soil. In this study, the evaporative cracking characteristics of soil with different saline concentrations were investigated. The results showed that the moisture content decreased linearly with the drying time in the early evaporation process, subsequently decreased slow down in the mid-term evaporation, and finally become got and remain a residual moisture content, which are $46.39 \%, 44.05 \%, 42.70 \%$, and $40.27 \%$ with the increase of the saline concentration. The evaporation process with different saline concentrations in the soil can be divided into three stages: uniform evaporation stage, slow down evaporation stage, and equilibrium evaporation stage, which was consistent with the moisture content change. With the development of the drying time, the cracks gradually appeared on the soil surface, gradually deepened in the soil, and expanded the crack network. The development of cracks can be divided into three stages: the cracking preparation stage, the crack development stage, and the crack stable stage. The cracking began at high evaporation rate under high saline concentration, and the fractal dimension remained stable under similar saline concentration. The fractal dimension was gradually increased with the decrease of the moisture content and the increase of the saline concentration, respectively. The soil began to crack with larger moisture under high saline concentration. The drying cracks in the nature were consistent with the configuration of the cracks formed in the experimental results.

\section{Introduction}

Saline soil is widely distributed in China and the world, which seriously harms the industry, agriculture, and infrastructure [1]. The chemical state of the saline soil is changed under the unique arid and semiarid climatic conditions, which can seriously affect the water evaporation and drying and cracking characteristics of the soil [2]. The saline soil showed the characteristics of expansion, poor water stability, and corrosiveness of the soil, which can cause salt expansion, settlement, and muddying of the roadbed [3]. Also, road reflection cracks can cause corrosion and cracking of roadbed pipelines, which seriously affects the stability of the road.
The embankment filled with high liquid limit or expansive soil tends to have a high natural moisture content due to the large plasticity of the soil. Water loss, volume shrinkage, and deformation of the saline soil appeared under the condition of high temperature exposure [4]. The surface water loss rate was much faster than the inner water loss rate in the compacted embankment. The uneven water loss leads to uneven soil shrinkage, which causes the horizontal network cracks on the surface of the embankment soil $[5,6]$. The cracks will widen and deepen as the exposure time increases and even will run through the whole layer.

Roadbed soil cracking is a common disease in road engineering, especially the high-filled roadbed with saline soil, causing uneven settlement of the roadbed and causing 
cracking. The high groundwater level and salinity degree may produce secondary salinization of the subgrade soil under the action of capillary water in winter and transpiration in summer [7]. The dynamic groundwater can intensify the increase of the soil moisture and salt content, which provide water and salt replenishment for the salt heave and frost heave of the highway [8]. Additionally, the large temperature fluctuation process, especially the cooling process, provides temperature conditions for salt expansion and also provides sufficient temperature stress for the moisture in the roadbed soil to move it to the top of the roadbed, thereby causing roadbed salt cracking $[9,10]$.

The saline soil is mainly sulfate and chloride salt, which are the main reasons for the failure and destruction of roadbeds. Soil shrinkage and cracking is a complex process, which is affected by various factors and has an important impact on the properties of the soil and causes various engineering problems [11]. Soil cracking reduces the bearing capacity of the soil and increases the compressibility of the soil, which leads to the cracking and destruction of the embankment soil and roadbed [12,13]. Cracks can also increase the permeability of the soil, adversely affecting the flow of groundwater, which eventually causes damage of the roadbed and embankment soil [14]. The embankment soil cracking circulates with the seasons and the humidity of the environment and is directly related to temperature [15]. These kinds of damage start from the side of the road and gradually develop toward the center of the road, which mainly formed the cracks and bulges with intertwined characteristics [16]. Meanwhile, the development of longitudinal cracks in the road surface is more obvious than the horizontal cracks and will eventually connect with each other to form a network [17].

At present, soil cracking and evaporation are quantitively analyzed using the correlation analysis, image process, and other chemical and biological methods [18-21]. The cracking mechanism was also investigated according to the crack behavior, crack initiation, and development [22]. Furthermore, the measures for controlling the soil cracking were comprehensively studied, such as adding the fiber and biochar into the soil to reinforce and improve the saline soil $[23,24]$.

However, the cracking and evaporation characteristics of embankment saline soil were barely considered in road engineering, especially the quantitative analysis of the crack development in the laboratory tests. In this study, the evaporation process and characteristics, cracking development, and influencing factors of the embankment saline soil were comprehensively investigated in different saline concentrations based on the experimental process and fractal theory. The moisture content, evaporation rate, and fractal dimension of the cracks were adopted to characterize the saline soil properties which are related to the embankment stability.

\section{Materials and Methods}

2.1. Materials. In this study, the laboratory experiments were adopted to investigate the cracking features of saline- alkali soil. The soil used in the experiment was collected at a depth of $0.5 \mathrm{~m} \sim 1.0 \mathrm{~m}$ in weak saline-alkaline groundwater environment, which was taken from Hailar Street, Hohhot, Inner Mongolia, China. Hohhot has a typical Mongolian plateau continental climate, with significant seasonal climate change, large annual temperature difference and large daily temperature difference, and sufficient sunshine. The annual average precipitation is $335.2 \sim 534.6 \mathrm{~mm}$, mainly in July and August.

The soil samples were dried and crushed outdoors before they were screened through a $2 \mathrm{~mm}$ sieve to remove large particles. Then, they were stored in sealed buckets for testing. The physical and mechanical properties of soil are listed in Table 1. Sodium sulfate $\left(\mathrm{Na}_{2} \mathrm{SO}_{4}\right)$ with an initial mass fraction of $38 \%$ was added to the soil to simulate the impact of saline-alkali pollution.

2.2. Experimental Process. Distilled water was added into the soil first and stirred well and evenly. After that, $\mathrm{Na}_{2} \mathrm{SO}_{4}$ was added into the soil sample to prepare the saturated mud with an initial moisture content of $100 \%$. The saline-alkali concentration was set as $0,0.12,0.24$, and $0.36 \mathrm{~mol} / \mathrm{L}$, separately. The soil samples were placed in a sealed round glass container with a size of $\Phi 19.5 \mathrm{~cm} \times 5 \mathrm{~cm}$. Then, they were stored in a container with the constant temperature and humidity for 10 days to provide enough time for the saline-alkali to react with the soil and produce uniform sample. The soil sample is shown in Figure 1. A total of 4 groups of samples were prepared for testing with different saline-alkali concentrations, and 3 soil samples in each group were tested in parallel. The experimental parameters are listed in Table 2.

The samples were placed in a constant temperature drying room together with the electronic balance and dried at the temperature of $25^{\circ} \mathrm{C}$ and a relative humidity of $60 \%$. The weight change was recorded every 3 hours by a computer during the drying process. The evaporation rate and moisture content of the sample were calculated to analyze the evaporation features. The definition of the evaporation is as follows [25]:

$$
E_{a}=\frac{\Delta m}{S \cdot T}
$$

where $\Delta m$ was the weight change of the soil, which is equal to the weight of the evaporated water, $S$ is the surface area of the soil sample, and $T$ is the evaporation time.

\subsection{Image Processing of Cracks in the Samples. A digital} camera was used to record the cracking development of the soil sample during the drying process. The recorded images were firstly processed to eliminate digital noise and interference to highlight the cracks using the median filter method to improve the image quality, which can be well used to quantitively analyze the crack features in the soil samples. The color image was converted to the grayscale image which can efficiently extract the crack information. Grayscale is usually divided into 256 grayscale shades, represented by numbers between 0 and 255. The darkest and brightest grayscales were represented by the numbers 0 and 255, 
TABle 1: Physical and mechanical properties of soil.

\begin{tabular}{|c|c|c|c|c|c|c|c|}
\hline $\begin{array}{l}\text { Density } \\
\left(\mathrm{g} \cdot \mathrm{cm}^{-3}\right)\end{array}$ & $\begin{array}{l}\text { Liquid limit } \\
(\%)\end{array}$ & $\begin{array}{l}\text { Plastic limit } \\
(\%)\end{array}$ & $\begin{array}{l}\text { Plastic } \\
\text { index }\end{array}$ & $\begin{array}{c}\text { Cohesion } \\
(\mathrm{kPa})\end{array}$ & $\begin{array}{c}\text { Internal friction } \\
\text { angle }\left({ }^{\circ}\right)\end{array}$ & $\begin{array}{l}\text { Compressibility coefficient } \\
\left(\mathrm{MPa}^{-1}\right)\end{array}$ & $\begin{array}{l}\text { Compressibility } \\
\text { modulus (MPa) }\end{array}$ \\
\hline 1.68 & 66.26 & 38.68 & 30.42 & 58.13 & 22.15 & 0.267 & 10.116 \\
\hline
\end{tabular}

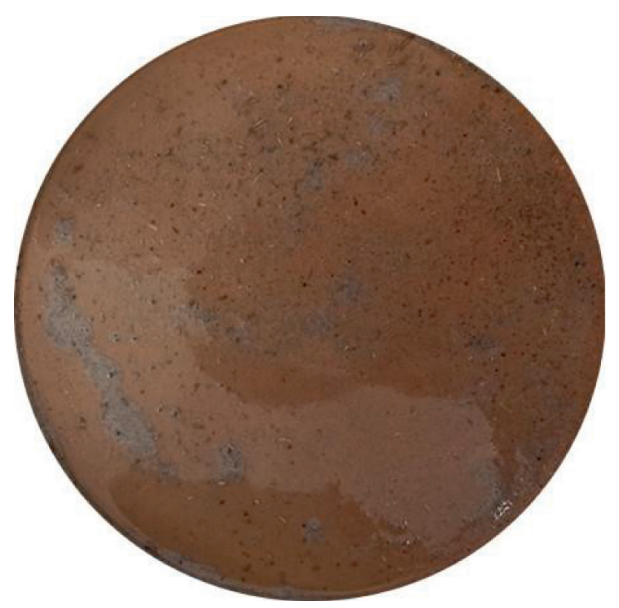

Figure 1: Soil sample.

TABLE 2: Experimental parameters.

\begin{tabular}{lccc}
\hline Soil group & Saline-alkali concentration $\left(\mathrm{mol} \cdot \mathrm{L}^{-1}\right)$ & Number of samples & Thickness of soil samples $(\mathrm{mm})$ \\
\hline 1 & 0 & 3 & 5 \\
2 & 0.12 & 3 & 5 \\
3 & 0.24 & 3 & 5 \\
4 & 0.36 & 3 & 5 \\
\hline
\end{tabular}

respectively. The gradient from black to white is represented by the remaining numbers from 1 to 254 . With grayscale, only one number is used to represent the color of each pixel.

The threshold segmentation method was used to binarize the image to further distinguish the cracks from other parts of the soil surface according to the gray threshold difference between the target object (a crack in this case) and the object background (uncracked soil surface). The image was considered as a combination of different gray levels in the target and the background. The target object indicates that the gray value of a pixel exceeds the threshold; otherwise, it belongs to the background.

In this study, the fractal dimension, which is a parameter used to quantitively characterize the irregularity of the system, was used to quantitively characterize the development of the cracks on the soil surface. Of which, similar dimension is a parameter used to characterize the fractal feature of the rock and soil mass and geological structures. Suppose that whole $S$ is composed of $N$ small individuals. These small individuals are denoted as $S_{i}(i=1,2, \ldots, N)$. If the small individuals are magnified by $1 / r_{i}$ times, they can be congruent with the whole $\left(0<r_{i}<1\right)$, and the similarity dimension is expressed as follows [26]:

$$
D_{S}=\frac{\ln N}{\ln (1 / r)}
$$

\section{Experimental Results}

3.1. Evaporation Process of the Saline-Alkali Soil. The evaporation of soil moisture is the process by which water enters the atmosphere from the soil surface, resulting in a decrease in the moisture content of the soil surface and gradual drying, leading to soil cracking, settlement deformation, soil salinization, and desertification. Especially for the embankment soil, evaporation and moisture content not only affect the cracking and deformation of the foundation but also lead to the cracking and subsidence of the pavement. The characteristics of the moisture content varying with the drying time are shown in Figure 2. The moisture content decreased with the drying time. During the first $120 \mathrm{~h}$ drying time, the moisture content decreased linearly with the drying time, and with the increase of the saline concentration, the moisture content of the soil was decreased to $65.39 \%$, $62.75 \%, 61.94 \%$, and $61.19 \%$, respectively. It decreased slow down and presented the curve reduction during the drying time from $120 \mathrm{~h}$ to $225 \mathrm{~h}$, and the moisture content was 


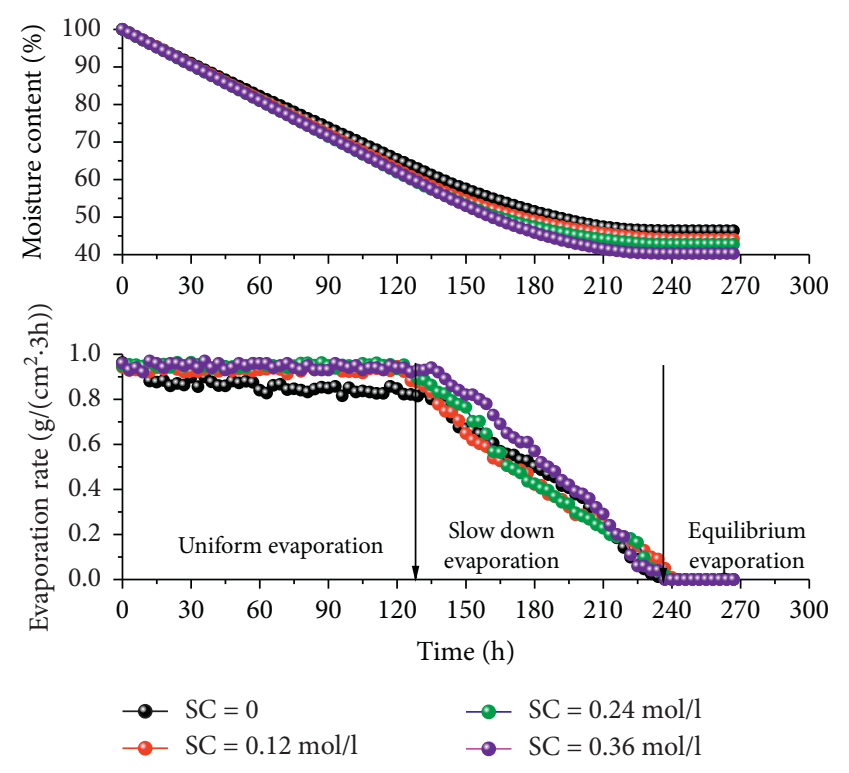

Figure 2: Moisture content and evaporation rate varying with drying time under different saline concentrations.

decreased to $46.57 \%, 44.58 \%, 43.07 \%$, and $40.47 \%$, respectively, with the increase of the saline concentration. After $225 \mathrm{~h}$ of the drying time, the moisture content of the soil gradually becomes steady and remain a value of $46.39 \%$, $44.05 \%, 42.70 \%$, and $40.27 \%$, under the saline concentration of $0,0.12,0.24$, and $0.36 \mathrm{~mol} / \mathrm{L}$, respectively. Moreover, the decrease trend of the moisture content gradually increases with the increase of the saline concentration, which indicated that saline may intensify water loss of the soil.

The evaporation was affected not only by the climate and the moisture content but also by the nature of the soil. During the drying time, the evaporation process with different saline concentrations in the soil can be divided into three stages: uniform evaporation stage, slow down evaporation stage, and equilibrium evaporation stage, as shown in Figure 2.

The initial soil sample was in a saturated state under the constant humidity and temperature conditions, which was characterized by uniform evaporation. The capillary water can completely supplement the water reduced by evaporation on the soil surface, which indicates that the evaporation force was greater than or close to the molecular force of water on the soil surface. The evaporation rate was steady in the first $120 \mathrm{~h}$ drying time which is consistent with the moisture content change. This indicates that the evaporation in this stage was controlled by the environmental conditions such as humidity and temperature. The average evaporation rate at this stage was about $0.86,0.93$, 0.95 , and $0.95 \mathrm{~g} /\left(\mathrm{cm}^{2} \cdot 3 \mathrm{~h}\right)$, respectively, under the saline concentrations of $0,0.12,0.24$, and $0.36 \mathrm{~mol} / \mathrm{L}$. The evaporation rate decreases with the increase of time, and the soil moisture content continues to decrease with the increase of saline concentration. Due to the low moisture content, the penetration rate of the deep water to the surface of the sample was far behind the loss rate of the surface water molecules, and the water flow from the bottom to the surface of the sample was not enough to maintain a constant evaporation rate, which resulting the decrease of the evaporation rate.

When the moisture content dropped to a certain level, the evaporation began to slow down. Also, with the increase of the saline concentration, the duration of the slow down stage gradually decreased. During the drying time from $120 \mathrm{~h}$ to $240 \mathrm{~h}$, the average evaporation rate was decreased to $0.45,0.45,0.46$, and $0.53 \mathrm{~g} /\left(\mathrm{cm}^{2} \cdot 3 \mathrm{~h}\right)$ with the increase of the saline concentration. Also, until $240 \mathrm{~h}$ of the drying time, the soil stopped evaporating, which was consistent with the change of the moisture content. These indicate that the soil moisture content gradually became a factor controlling the evaporation rate, while the effect of environmental conditions gradually weakens in the slow down stage. This stage will continue until the soil surface dries out.

When the moisture content drops below the ambient humidity, the evaporation and water absorption process was slowly balanced, showing the characteristics of slow equilibrium evaporation. The surface and inside of the soil are so dry that there is no or not enough water in the soil that can be transported to the surface, which leads to the termination of surface evaporation. The water in the soil evaporates and escapes through the dry surface through molecular diffusion. The water evaporation rate was very slow and mainly controlled by the soil moisture content below the surface and the soil water vapor pressure gradient. At this stage, the soil surface moisture content was equal to the residual moisture content, and the evaporation rate was 0 . Also, the saline concentration has no significant effect on the evaporation rate.

\subsection{Cracking Characteristics of the Soil under Different Saline} Concentrations. The soil in nature consists of liquid, solid, and gas phases, which is a three-phase structure. The pores are filled with liquid water under the saturated state. Due to evaporation and water loss process, the liquid phase and the moisture content gradually decrease and then lead to the cracking on the soil surface. The developed cracks may become the preferential path for water migration and increase the permeability of the soil, resulting in a decrease in the mechanical strength of the soil and reducing the stability of the road subgrade. Figure 3 shows the cracks on the soil. With the development of the drying time, the cracks gradually appeared on the soil surface, gradually deepened in the soil, and expanded the crack network.

The effect of saline concentration on the degree of fracture development is significantly different. During the drying process, the decrease of the moisture content causes suction reduction and volume shrinkage of the soil body, which destroyed the skeleton structure and generates tensile stress due to the unevenness of the internal water loss and shrinkage of the soil body. The cracks will appear when the tensile stress exceeds the tensile strength of the soil. The fractal dimension can quantitatively characterize the degree of crack development. As shown in Figure 4, the cracks could not form during early drying which indicated that the fractal dimension was 0 . Also, with the increase of the saline 


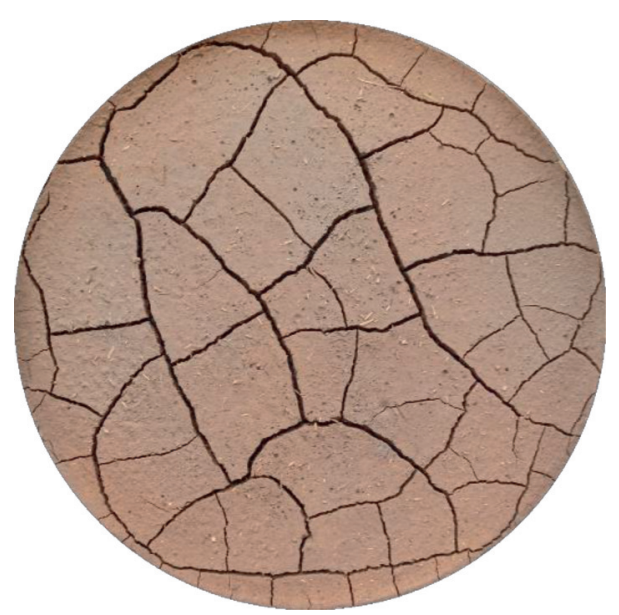

Figure 3: Cracks on the soil surface.

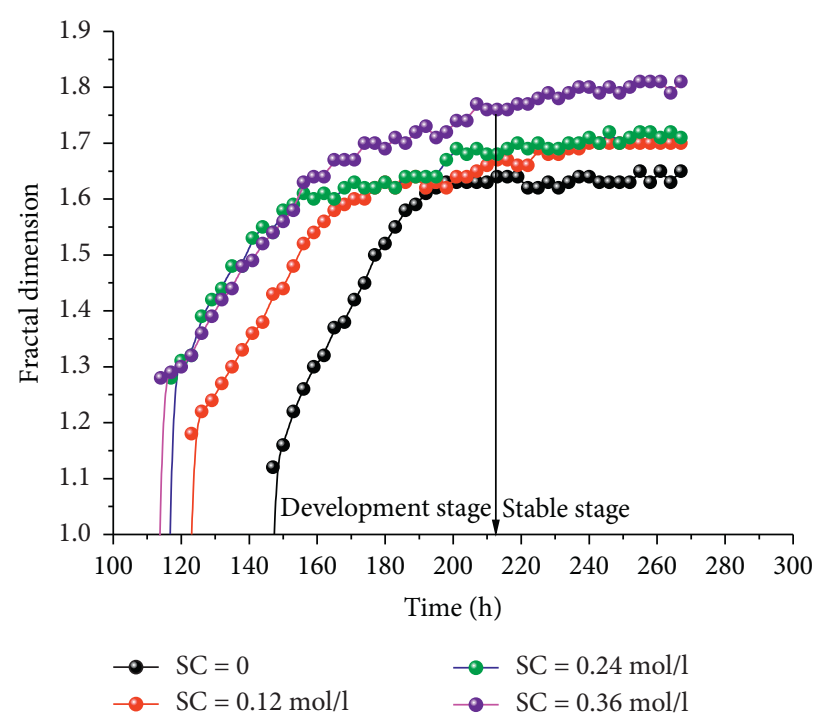

Figure 4: Fractal dimension varying with drying time under different drying times.

concentration, the cracking time was lagging. During the drying time of $100 \mathrm{~h}$ and $220 \mathrm{~h}$, the fractal dimension gradually increased, and the higher the saline concentration, the longer the cracking time. After the drying time of $220 \mathrm{~h}$, the fractal dimension remained unchanged as the cracks no longer developed. With the increase of the saline concentration, the final fractal dimension was gradually increased. According to the cracking characteristics, the development of cracks can be divided into three stages: the cracking preparation stage, the crack development stage, and the crack stable stage. With the increase of the saline concentration, the time for cracks to occur gradually decreases, and the time for cracks to develop gradually increases.

With the decrease of the moisture content, the tensile stress gradually increased and accumulated energy to crack readily. With the development of drying time, the cracks firstly appeared on the soil surface. Due to the suction in the soil, the adjacent cracks were connected and formed the main crack in the soil. The new cracks began to branch out from the main cracks, forming secondary cracks during the development stage. The branch cracks further developed in the large-area block formed by the secondary cracks, thereby forming a complete secondary crack network. During the stable phase of the development of the crack network, no new cracks appear on the soil surface even if the evaporation continues. As the drying continued, the existing cracks gradually expanded until they eventually stabilized. The surface crack network basically has no change in the surface crack network morphology, but the cracks widen and deepen.

\section{Discussion}

4.1. Relationships between the Fractal Dimension and Moisture Content and Evaporation Rate. Figure 5(a) shows the fractal dimension varying with the moisture content under different saline concentrations. With the decrease of the moisture content, the fractal dimension gradually 


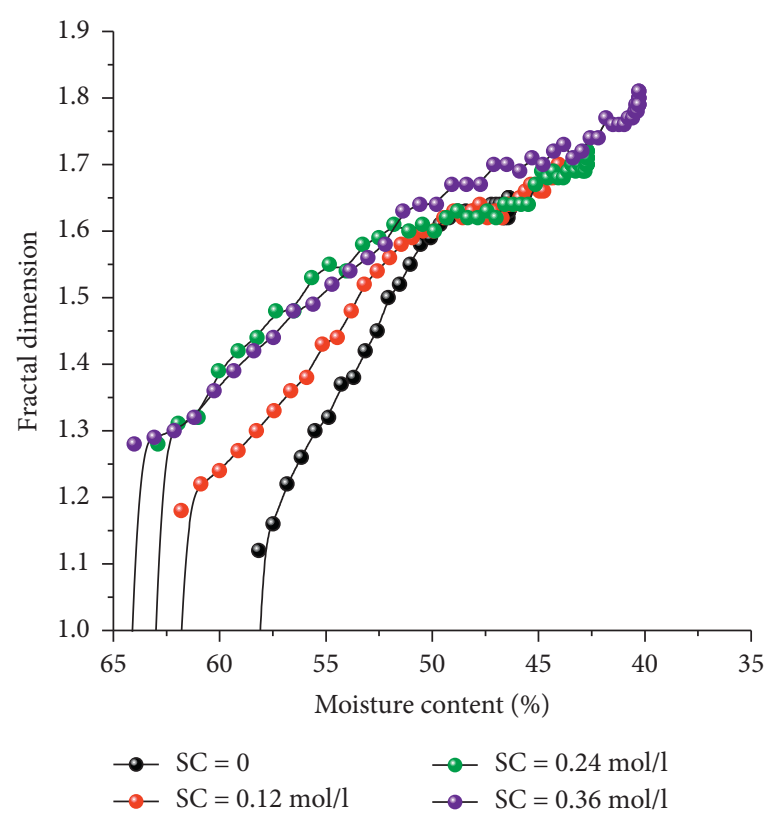

(a)

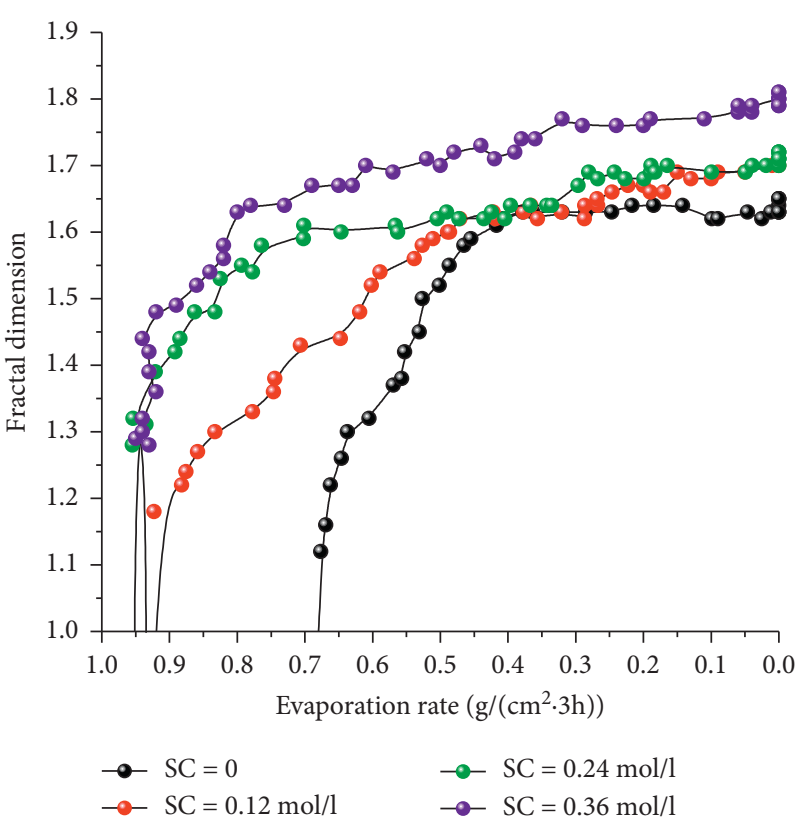

(b)

FIGURE 5: Fractal dimension varying with moisture content and evaporation rate under different saline concentrations. (a) Fractal dimension varying with moisture content. (b) Fractal dimension varying with evaporation rate.

increased. Also, the fractal dimension increased with the increase of the saline concentration, which indicated that the saline can promote the development of the cracks. The higher the evaporation rate was, the faster the fractal dimension developed, as shown in Figure 5(b). With the decrease of the evaporation rate, the fractal dimension was gradually stable. The cracking began at high evaporation rate under high saline concentration, and the fractal dimension remained stable under similar saline concentration, which indicated that the evaporation rate has little effect on the cracking during the stable stage.

\subsection{Effect of Saline on the Moisture Content and Cracking} Time. Figure 6 shows that the cracking moisture content and the cracking time increased with the saline concentration, while the residual moisture content decreased. The cracking moisture content was $58.16 \%, 61.8 \%, 62.9 \%$, and $64.01 \%$, respectively, under the saline concentrations of 0 , $0.12,0.24$, and $0.36 \mathrm{~mol} / \mathrm{L}$, while the residual moisture content was $46.39 \%, 44.05 \%, 42.70 \%$, and $40.27 \%$, respectively. Results indicated that the saline reacted with the soil which reduced the hydrophilic properties and adsorbability of the soil, resulting in lower residual moisture content and longer cracking time. With the increase of the cracking time, the cementation between soil particles reduced which in turn promoted the development of cracks. The soil began to crack with the larger moisture under high saline concentration which indicated that saline can reduce the tensile strength of the soil and weaken the stability of the structure of the soil [27].

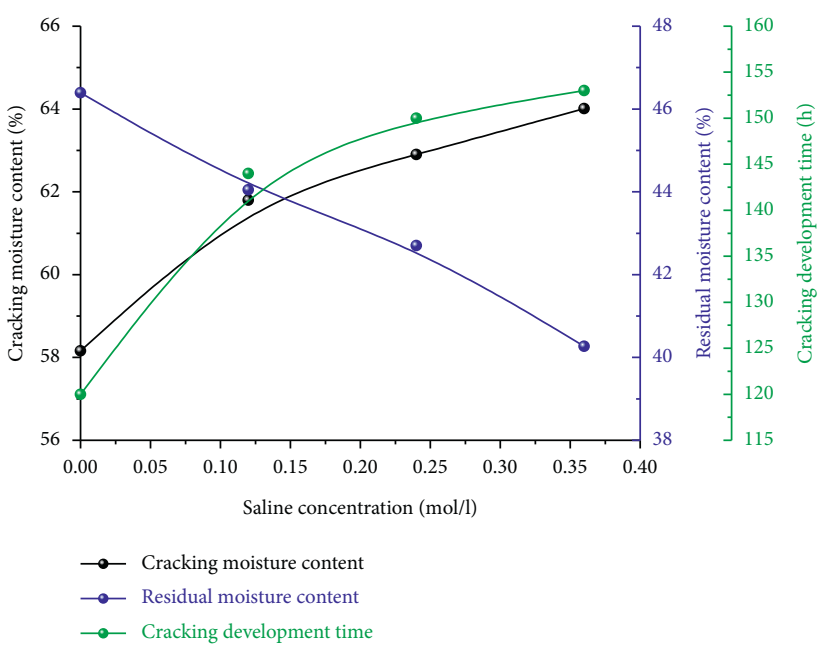

Figure 6: Cracking moisture content, residual moisture content, and cracking duration varying with saline concentration.

\subsection{Effect of Saline on the Cracking Degree and Evaporation} Rate. Figure 7 shows that maximum fractal dimension and the average evaporation rate increased with the increase of the saline concentration. During the crack stable stage, the maximum fractal dimension was $1.65,1.7,1.71$, and 1.81, respectively, with the increase of the saline concentration, which indicated that the saline may aggravate the development of cracks and finally affect the stability of embankment soil. The saline in the soil may induce the disintegration of the soil aggregate structure which provided the space and channel for the water evaporation and lead to the high evaporation rate. 


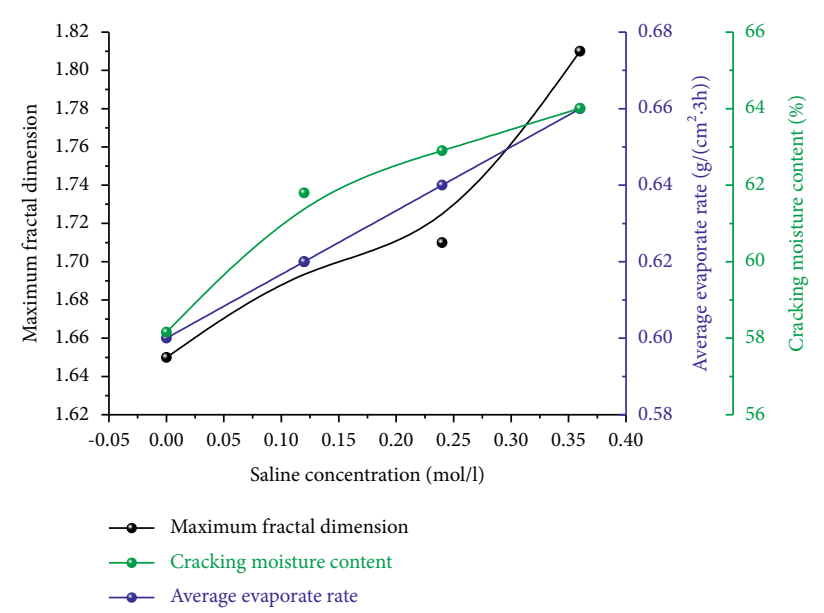

FIGURE 7: Maximum fractal dimension, average evaporation rate, and cracking moisture content varying with saline concentration.

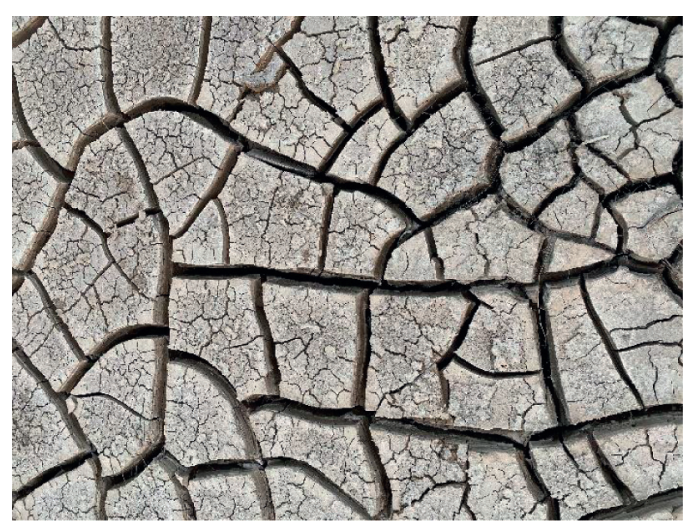

(a)

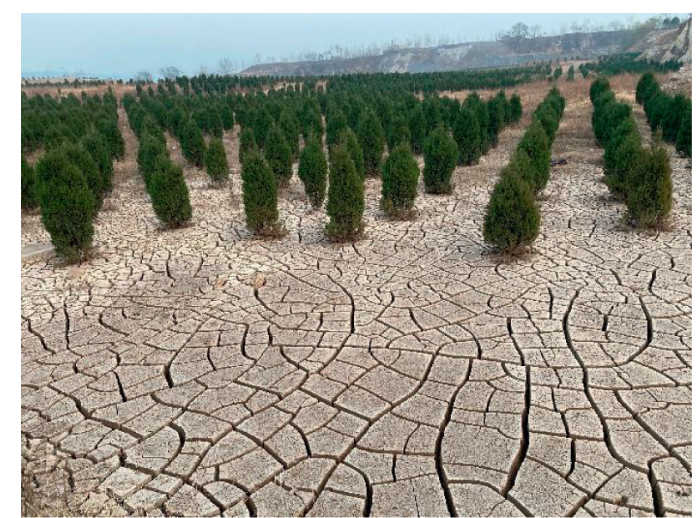

(b)

Figure 8: Drying cracks in the nature and the corresponding control measures. (a) Drying cracks in the nature. (b) Control measures for the cracks by tree planting.

The drying cracks were common in nature, as shown in Figure 8(a), which was consistent with the configuration of the cracks formed in the experimental results. The crack network was complicated and difficult to characterize, which was suitable for quantization of fractal dimension. In practical engineering processes, tree planting management was commonly used to control the crack development (Figure 8(b)), as the plant roots can effectively keep moisture from losing and reinforce the soil structure.

In the further study, the mechanical and microstructure mechanism of the saline soil affecting the cracking and evaporation characteristics should be addressed.

\section{Conclusions}

The saline in the soil significantly changed the evaporation characteristics of the soil and the development of dry cracks. The moisture content decreased linearly with the drying time in the early evaporation process, subsequently decreased slow down in the mid-term evaporation, and finally got steady and remain a value of $46.39 \%, 44.05 \%, 42.70 \%$, and $40.27 \%$ with the increase of the saline concentration. The evaporation process with different saline concentrations in the soil can be divided into three stages: uniform evaporation stage, slow down evaporation stage, and equilibrium evaporation stage, which was consistent with the moisture content change. The evaporation rate was steady in the first $120 \mathrm{~h}$ drying time, then gradually slowed down when the moisture content dropped to a certain level, and finally stopped evaporating until the soil surface dried out when the moisture content dropped below the ambient humidity. The evaporation and water absorption processes were slowly balanced, showing the characteristics of slow equilibrium evaporation.

With the development of the drying time, the cracks gradually appeared on the soil surface, gradually deepened in the soil, and expanded the crack network. With the increase of the saline concentration, the final fractal dimension was gradually increased. The development of cracks can be divided into three stages: the cracking preparation stage, the crack development stage, and the crack stable stage. With the increase of the saline concentration, the time for cracks to occur gradually decreases, and the time for cracks to develop gradually increases. The fractal dimension was gradually 
increased with the decrease of the moisture content and the increase of the saline concentration, respectively. The cracking began at high evaporation rate under high saline concentration, and the fractal dimension remained stable under similar saline concentration. The cracking moisture content was $58.16 \%, 61.8 \%, 62.9 \%$, and $64.01 \%$, respectively, under the saline concentrations of $0,0.12,0.24$, and $0.36 \mathrm{~mol} / \mathrm{L}$. The soil began to crack with the larger moisture under high saline concentration. The drying cracks in the nature were consistent with the configuration of the cracks formed in the experimental results. Also, tree planting management was commonly used to control the crack development in practical engineering processes.

\section{Data Availability}

The datasets generated during the current study are available from the corresponding author upon reasonable request.

\section{Conflicts of Interest}

The authors declare that they have no conflicts of interest.

\section{Acknowledgments}

This study was supported by the Science and Technology Project of Henan Province under grant nos. 212102310596 and 212102310939 and the Henan College Students' Innovation and Entrepreneurship Training Program under grant no. S202110480034. The authors are grateful for the financial support.

\section{References}

[1] J. Li, L. Pu, M. Zhu, and R. Zhang, "The present situation and hot issues in the salt-affected soil research," Acta Geographica Sinica, vol. 67, no. 9, pp. 1233-1245, 2012.

[2] M. Tejada, C. Garcia, J. L. Gonzalez, and M. T. Hernandez, "Use of organic amendment as a strategy for saline soil remediation: influence on the physical, chemical and biological properties of soil," Soil Biology and Biochemistry, vol. 38, no. 6, pp. 1413-1421, 2006.

[3] D. Li, B. Yang, C. Yang, Z. Zhang, and M. Hu, "Effects of salt content on desiccation cracks in the clay," Environmental Earth Sciences, vol. 80, no. 19, pp. 1-13, 2021.

[4] B. Yang and J. Yuan, "Influence of soda content on desiccation cracks in clayey soils," Soil Science Society of America Journal, vol. 83, no. 4, pp. 1054-1061, 2019.

[5] C.-S. Tang, Y.-J. Cui, B. Shi, A.-M. Tang, and C. Liu, "Desiccation and cracking behaviour of clay layer from slurry state under wetting-drying cycles," Geoderma, vol. 166, no. 1, pp. 111-118, 2011.

[6] N. An, C.-S. Tang, S.-K. Xu, X.-P. Gong, B. Shi, and H. I. Inyang, "Effects of soil characteristics on moisture evaporation," Engineering Geology, vol. 239, pp. 126-135, 2018.

[7] Z. Xiao, Y. Lai, and M. Zhang, "Study on the freezing temperature of saline soil," Acta Geotechnica, vol. 13, no. 1, pp. 195-205, 2018.

[8] X. Zhang, S. Liu, Q. Wang et al., "Experimental investigation of water migration characteristics for saline soil," Polish
Journal of Environmental Studies, vol. 28, no. 3, pp. 14951505, 2019.

[9] B. Bai, Q. Nie, Y. Zhang, X. Wang, and W. Hu, "Cotransport of heavy metals and $\mathrm{SiO} 2$ particles at different temperatures by seepage," Journal of Hydrology, vol. 597, Article ID 125771, 2021.

[10] B. Bai, G.-C. Yang, T. Li, and G.-S. Yang, "A thermodynamic constitutive model with temperature effect based on particle rearrangement for geomaterials," Mechanics of Materials, vol. 139, Article ID 103180, 2019.

[11] B. Yang, D. Li, S. Yuan, and L. Jin, "Role of biochar from corn straw in influencing crack propagation and evaporation in sodic soils," Catena, vol. 204, Article ID 105457, 2021.

[12] B. Yuan, Z. Li, Z. Zhao, H. Ni, Z. Su, and Z. Li, "Experimental study of displacement field of layered soils surrounding laterally loaded pile based on transparent soil," Journal of Soils and Sediments, vol. 21, no. 9, pp. 3072-3083, 2021.

[13] B. Yuan, Z. Li, Y. Chen et al., "Mechanical and microstructural properties of recycling granite residual soil reinforced with glass fiber and liquid-modified polyvinyl alcohol polymer," Chemosphere, vol. 286, Article ID 131652, 2022.

[14] Q. Cheng, C.-S. Tang, D. Xu, H. Zeng, and B. Shi, "Water infiltration in a cracked soil considering effect of dryingwetting cycles," Journal of Hydrology, vol. 593, Article ID 125640, 2021.

[15] C.-S. Tang, D.-Y. Wang, B. Shi, and J. Li, "Effect of wettingdrying cycles on profile mechanical behavior of soils with different initial conditions," Catena, vol. 139, pp. 105-116, 2016.

[16] B. Yang, J. Liu, X. Zhao, and S. Zheng, "Evaporation and cracked soda soil improved by fly ash from recycled materials," Land Degradation \& Development, vol. 32, no. 9, pp. 2823-2832, 2021.

[17] B. Yang, K. Xu, and Z. Zhang, "Mitigating evaporation and desiccation cracks in soil with the sustainable material biochar," Soil Science Society of America Journal, vol. 84, no. 2, pp. 461-471, 2020.

[18] J. Ren, X. Li, and K. Zhao, "Quantitative analysis of relationships between crack characteristics and properties of soda-saline soils in Songnen Plain, China," Chinese Geographical Science, vol. 25, no. 5, pp. 591-601, 2015.

[19] C. Liu, C.-S. Tang, B. Shi, and W.-B. Suo, "Automatic quantification of crack patterns by image processing," Computers \& Geosciences, vol. 57, pp. 77-80, 2013.

[20] B. Liu, C. Zhu, C.-S. Tang et al., "Bio-remediation of desiccation cracking in clayey soils through microbially induced calcite precipitation (MICP)," Engineering Geology, vol. 264, Article ID 105389, 2020.

[21] C.-S. Tang, D.-Y. Wang, C. Zhu, Q.-Y. Zhou, S.-K. Xu, and B. Shi, "Characterizing drying-induced clayey soil desiccation cracking process using electrical resistivity method," Applied Clay Science, vol. 152, pp. 101-112, 2018.

[22] J. H. Li and L. M. Zhang, "Study of desiccation crack initiation and development at ground surface," Engineering Geology, vol. 123, no. 4, pp. 347-358, 2011.

[23] C.-S. Tang, B. Shi, Y.-J. Cui, C. Liu, and K. Gu, "Desiccation cracking behavior of polypropylene fiber-reinforced clayey soil," Canadian Geotechnical Journal, vol. 49, no. 9, pp. 1088-1101, 2012.

[24] Y. Zhang, K. Gu, J. Li, C. Tang, Z. Shen, and B. Shi, "Effect of biochar on desiccation cracking characteristics of clayey soils," Geoderma, vol. 364, Article ID 114182, 2020.

[25] B. Yang, Z. Zhang, W. Ma, M. Hu, and Y. Zhang, "Effect of tea waste on cracking of foundation soil," Advances in Civil Engineering, vol. 2021, Article ID 7525811, 7 pages, 2021. 
[26] B. Yang, S. Du, X. Zhao, D. Tang, and C. Yang, "Decision making of curriculum attainment degree for engineering geology based on fuzzy set theory," Advances in Civil Engineering, vol. 2021, Article ID 1743778, 6 pages, 2021.

[27] B. Yuan, M. Sun, L. Xiong, Q. Luo, and H. Li, "Investigation of $3 \mathrm{~d}$ deformation of transparent soil around a laterally loaded pile based on a hydraulic gradient model test," Journal of Building Engineering, vol. 28, no. 6, Article ID 101024, 2019. 